\title{
The impact of uncorrected mild aortic insufficiency at the time of left ventricular assist device implantation
}

Yuki Tanaka, MD, ${ }^{\mathrm{a}}$ Tomohiro Nakajima, MD, PhD, ${ }^{\mathrm{a}}$ Irene Fischer, $\mathrm{MPH},{ }^{\mathrm{a}}$ Fei Wan, $\mathrm{PhD},{ }^{\mathrm{b}}$ Kunal Kotkar, MD, ${ }^{a}$ Marc R. Moon, MD, ${ }^{a}$ Ralph J. Damiano, Jr, MD, ${ }^{a}$ Muhammad F. Masood, MD, ${ }^{a}$ and Akinobu Itoh, $\mathrm{MD}, \mathrm{PhD}^{\mathrm{a}}$

\section{ABSTRACT}

Objective: The study objective was to investigate the progression of uncorrected mild aortic insufficiency and its impact on survival and functional status after left ventricular assist device implantation.

Methods: We retrospectively reviewed 694 consecutive patients who underwent implantation of a continuous-flow left ventricular assist device between January 2006 and March 2018. Pre-left ventricular assist device transthoracic echocardiography identified 111 patients with mild aortic insufficiency and 493 patients with trace or no aortic insufficiency. To adjust for differences in preoperative factors, propensity score matching was used, resulting in 101 matched patients in each of the mild aortic insufficiency and no aortic insufficiency groups.

Results: Although both groups showed similar survival $(P=.58)$, the mild aortic insufficiency group experienced higher incidence of readmission caused by heart failure (hazard ratio, 2.62; 95\% confidence interval, 1.42-4.69; $P<.01$ ). By using the mixed effect model, pre-left ventricular assist device mild aortic insufficiency was a significant risk factor for both moderate or greater aortic insufficiency and worsening New York Heart Association functional status $(P<.01)$.

Conclusions: Patients with uncorrected mild aortic insufficiency had a higher risk of progression to moderate or greater aortic insufficiency after left ventricular assist device implantation with worse functional status and higher incidence of readmission caused by heart failure compared with patients without aortic insufficiency. Further investigations into the safety and efficacy of concomitant aortic valve procedures for mild aortic insufficiency at the time of left ventricular assist device implant are warranted to improve patients' quality of life, considering the longer left ventricular assist device use as destination therapy and bridge to transplant with the new US heart allocation system. (J Thorac Cardiovasc Surg 2020;160:1490-500)

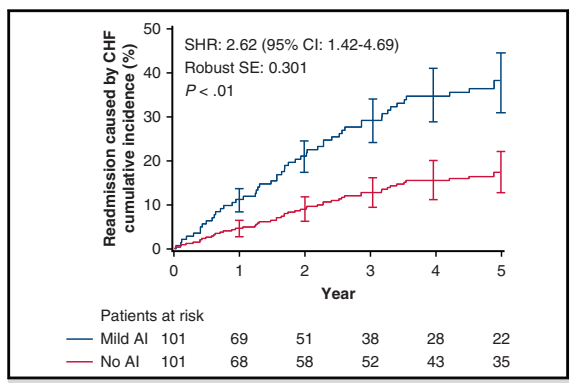

The cumulative incidence curve of first heart failure-related readmissions.

\section{CENTRAL MESSAGE}

Uncorrected mild Al with ventric-

ular assist device implant was

associated with later moderate or

severe Al, worse NYHA status, and

more incidence of heart failure.

\section{PERSPECTIVE}

Uncorrected mild Al with LVAD implant resulted in more Al progression, worse NYHA functional status, and more CHF-related readmissions than those without Al. These findings should help establish better treatment strategies for patients expected to be on LVAD longer with the new US heart allocation system.

See Commentaries on pages 1501,1502 , an 1503 .
From the ${ }^{\mathrm{a}}$ Division of Cardiothoracic Surgery, Department of Surgery, and ${ }^{\mathrm{b}}$ Division of Public Health Sciences, Department of Surgery, Washington University School of Medicine, Saint Louis, Mo.

Institutional Review Board approval number and date: \#201409140; 12/17/2018.

Read at the 99th Annual Meeting of The American Association for Thoracic Surgery, Toronto, Ontario, Canada, May 4-7, 2019.

Received for publication May 8, 2019; revisions received Feb 25, 2020; accepted for publication Feb 27, 2020; available ahead of print May 12, 2020.

Address for reprints: Akinobu Itoh, MD, PhD, Division of Cardiothoracic Surgery, Department of Surgery, Washington University School of Medicine, Campus Box 8234, 660 Euclid Ave, St. Louis, MO 63110 (E-mail: itoha@wustl.edu). 0022-5223

Copyright (C) 2020 The Author(s). Published by Elsevier Inc. on behalf of The American Association for Thoracic Surgery. This is an open access article under the CC BY-NC-ND license (http://creativecommons.org/licenses/by-nc-nd/4.0/). https://doi.org/10.1016/j.jtcvs.2020.02.144
Left ventricular assist device (LVAD) implantation has become a bridge to transplantation (BTT) or a destination therapy (DT) for patients with end-stage heart failure, improving the quality of life and survival. ${ }^{1-3}$ However, LVAD support

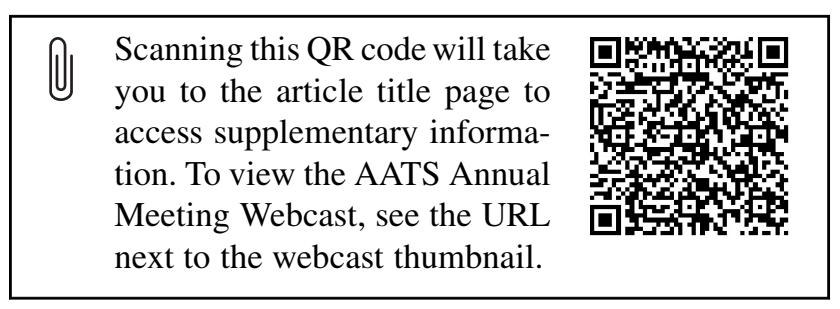




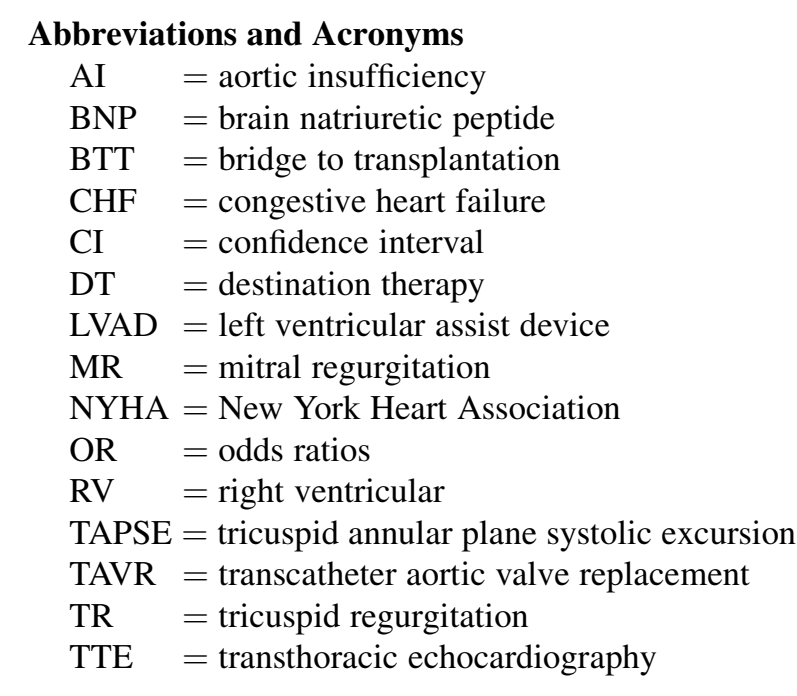

has some limitations, including the potential development of aortic insufficiency (AI). In previous studies, $25 \%$ to $59 \%$ of patients with no AI at baseline developed significant postLVAD AI. ${ }^{4-8}$ Risk factors identified for AI progression include a lower frequency of aortic valve opening, aortic root diameter enlargement, longer LVAD support duration, older age, and the use of a continuous-flow pump, especially an axial flow pump. ${ }^{5-7,9-13}$ Additionally, an animal study suggested that the outflow graft angle perpendicular to the aorta increased AI grade and recirculation. ${ }^{14}$ However, studies have not found a significant association between AI after LVAD implantation and survival. Additionally, the effects of post-LVAD AI on quality of life and physical status have not been fully investigated, ${ }^{6,8-10}$ and the relationship between preimplantation AI severity and the progression of the AI after LVAD implantation remains unclear. The latest International Society for Heart and Lung Transplantation guideline includes a Class I recommendation to consider surgical intervention at the time of LVAD implantation when the $\mathrm{AI}$ is moderate or greater. ${ }^{15}$ However, there is no consensus on the treatment strategy for patients with mild AI. The purpose of this retrospective study was to investigate the progression of uncorrected mild AI at the time of LVAD implantation and its impact on survival and functional status compared with patients with no $\mathrm{AI}$ at baseline.

\section{MATERIALS AND METHODS}

\section{Study Design and Patients}

The study protocol was approved by the Institutional Review Board of Washington University in St Louis (\# 201409140). Informed consent was obtained from all of the patients.

We retrospectively reviewed the data for 694 patients enrolled in the Washington University in St Louis Mechanical Circulatory Support Registry who underwent implantation of continuous-flow LVADs between January 2006 and March 2018. The implanted devices were a HeartMate 2 (Abbott, Abbott Park, Ill) or HeartWare (Medtronic, Minneapolis,
Minn). The study excluded any patients who underwent a concomitant aortic valve procedure at the time of LVAD implantation, who received a biventricular assist device, or who had incomplete data. This resulted in a total of 604 patients being enrolled in the study (Figures 1 and 2).

Before the implantation, each patient underwent an assessment of AI severity by transthoracic echocardiography (TTE). This identified mild $\mathrm{AI}$ in 111 patients and trace or no $\mathrm{AI}$ in 493 patients. As described in a later section ("Propensity Score Matching"), preoperative factors were assessed with propensity scores, and 101 patients with mild AI (Mild AI group) were matched to 101 patients with trace or no AI (no AI group, Figures 1 and 2). Follow-up echocardiography parameters, New York Heart Association (NYHA) functional class, readmission rate, and survival were compared between the 2 groups. The primary end point was defined as the progression of AI to moderate or greater after LVAD implantation. The secondary end points were NYHA functional class, readmission rate, and survival. A further risk factor analysis for progression to moderate or greater AI was performed for all 111 patients with pre-LVAD mild AI (Appendix E1).

\section{Data Collection and Follow-up}

Demographic, echocardiographic, and outcome variables were extracted from electronic medical records and the institutional mechanical circulatory support registry database. The demographic and echocardiographic data were used to characterize the patients before LVAD implantation. Operative data, such as cardiopulmonary bypass time and details about other valvular procedures, were also obtained.

The pre-LVAD grades of AI, mitral regurgitation (MR), and tricuspid regurgitation (TR) were obtained from the results of TTE acquired within 30 days before the LVAD implantation. The post-LVAD TTE parameters were collected from all echocardiogram measurements during the follow-

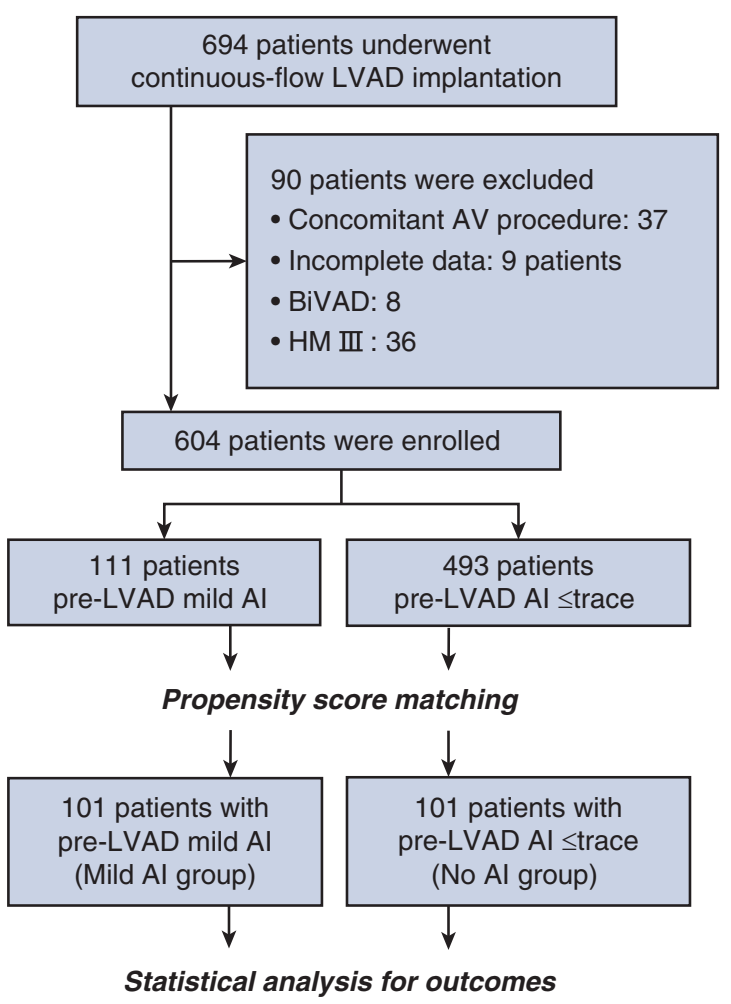

FIGURE 1. Patient enrollment. $L V A D$, Left ventricular assist device; $A V$, aortic valve; $B i V A D$, biventricular assist device; $H M$, HeartMate; $A I$, aortic insufficiency. 


\begin{tabular}{|c|c|c|c|}
\hline - Methods & $\begin{array}{c}\text { January } 2006 \text { - March } 2018 \\
694 \text { LVAD patients } \\
\text { No AV intervention } \\
604 \text { patients }\end{array}$ & \multicolumn{2}{|c|}{$\begin{array}{l}90 \text { patients were excluded } \\
\text { - Concomitant AV procedure } \\
\text { - Incomplete data } \\
\text { - BiVAD } \\
\text { - HeartMate } 3\end{array}$} \\
\hline $\begin{array}{c}\text { Mild Al: pre-LVAD mild AI } \\
111 \text { patients }\end{array}$ & 1:1 propensity score matching & \multicolumn{2}{|c|}{$\begin{array}{c}\text { No Al: pre-LVAD Al } \leq \text { trace } \\
493 \text { patients }\end{array}$} \\
\hline \multicolumn{4}{|l|}{ - Results } \\
\hline & Estimate & SE & $P$-value \\
\hline \multicolumn{4}{|l|}{ Post-LVAD Al $\geq \bmod$} \\
\hline $\begin{array}{l}\text { Mild AI } \\
\text { LVAD support duration }\end{array}$ & $\begin{array}{l}2.03 \\
0.71\end{array}$ & $\begin{array}{l}0.36 \\
0.12\end{array}$ & $\begin{array}{l}<.01 \\
<.01\end{array}$ \\
\hline \multicolumn{4}{|l|}{ Post-LVAD MR $\geq \bmod$} \\
\hline $\begin{array}{l}\text { Mild Al } \\
\text { LVAD support duration }\end{array}$ & $\begin{array}{l}0.95 \\
0.51\end{array}$ & $\begin{array}{l}0.26 \\
0.11\end{array}$ & $\begin{array}{l}<.01 \\
<.01\end{array}$ \\
\hline \multicolumn{4}{|l|}{ Post-LVAD TR $\geq \bmod$} \\
\hline $\begin{array}{l}\text { Mild Al } \\
\text { LVAD support duration }\end{array}$ & $\begin{array}{l}0.74 \\
0.09\end{array}$ & $\begin{array}{l}0.23 \\
0.09\end{array}$ & $\begin{array}{r}<.01 \\
.33\end{array}$ \\
\hline \multicolumn{4}{|c|}{ Post-LVAD NYHA $\geq$ Class III } \\
\hline Mild Al & 1.19 & 0.25 & $<.01$ \\
\hline LVAD support duration & 0.13 & 0.09 & .13 \\
\hline
\end{tabular}

FIGURE 2. Summary of the methods and main results of this study. The generalized linear mixed models included all post-LVAD echocardiograms and NYHA data with sample sizes of 281 in the mild AI group and 241 in the no AI group, which were adjusted with propensity score-matched pairs. The generalized mixed-effect models demonstrated that pre-LVAD mild AI was a risk factor for post-LVAD moderate or greater AI $(P<.01)$, MR $(P<.01)$, TR $(P<.01)$, and worse NYHA functional status $(P<.01)$. Longer LVAD support was significantly associated with progression to moderate or greater $\mathrm{AI}(P<.01)$ and $\mathrm{MR}(P<.01) . L V A D$, Left ventricular assist device; $A V$, aortic valve; $B i V A D$, biventricular assist device; $A I$, aortic insufficiency; $S E$, standard error; $\geq \bmod$, moderate or greater; $M R$, mitral valve regurgitation; $T R$, tricuspid valve regurgitation; NYHA, New York Heart Association.

up term. These assessments were based on regurgitation jet width in the parasternal short- and long-axis views. According to the recommendations of the American Society of Echocardiography, ${ }^{16}$ the scoring was defined as none, trace, mild, moderate, or severe. Outcomes including readmission, NYHA classification, and mortality were reviewed for all of the patients. PostLVAD brain natriuretic peptide (BNP) levels and NYHA functional class were collected at the same time as the echocardiogram measurements. Drop-out and end of study period were regarded as censoring events.

\section{Propensity Score Matching}

One-to-one propensity score matching was performed using the propensity score matching module of SPSS Statistics version 25 (IBM, Armonk, NY). Propensity scores for the mild AI and no AI groups were obtained from logistic regression analysis using the following pre-LVAD variables in the propensity model: age, body mass index, Interagency Registry for Mechanically Assisted Circulatory Support profile, ischemia, indication, device implanted, NYHA classification, cardiogenic shock, resuscitation, mitral valve procedure, tricuspid valve procedure, sclerotic aortic valve, left ventricle ejection fraction, tricuspid annular plane systolic excursion (TAPSE), moderate or greater MR, moderate or greater TR, and systemic pulmonary artery pressure. One-to-one matching was performed with a caliper width of 0.1 of the pooled standard deviation of the logit of the propensity score. Standardized differences were compared between 2 groups before and after propensity score matching, and |standardized difference| 0.1 or greater was considered statistically significant. It was confirmed that all preoperative factors were well matched between the 2 groups based on the standardized differences (Tables 1 and 2). The resulting scorematched pairs were used for the outcome analyses. All of the propensity score-matching processes were performed with the oversight of a statistician. ${ }^{17}$

\section{Statistical Analysis}

SPSS Statistics version 25 (IBM Corp) and SAS version 9.4 (SAS Institute, Inc, Cary, NC) were used for the data analysis. The results for quantitative variables are presented as the mean \pm standard deviation or median and selected quantiles (25th-75th percentile); categorical variables are summarized as absolute frequencies and percentages. Continuous variables were compared using Student $t$ test and the Mann-Whitney $U$ test. Categorical variables were compared using Pearson's chi-square test, except when the expected frequencies were less than 5, in which case the Fisher exact test was used. In the propensity score-matched sample, the subjects were pair-matched. Each subject in the mild AI or no AI groups could have 1 or more than 1 echocardiogram measurements at different time intervals. The serial observations from each subject were correlated. To control for the potential correlation between matched pairs and the correlation of repeated measurements within each subject, we analyzed longitudinal 
TABLE 1. Comparisons of demographic and clinical characteristics between patients with the mild aortic insufficiency and no aortic insufficiency groups before and after propensity score matching

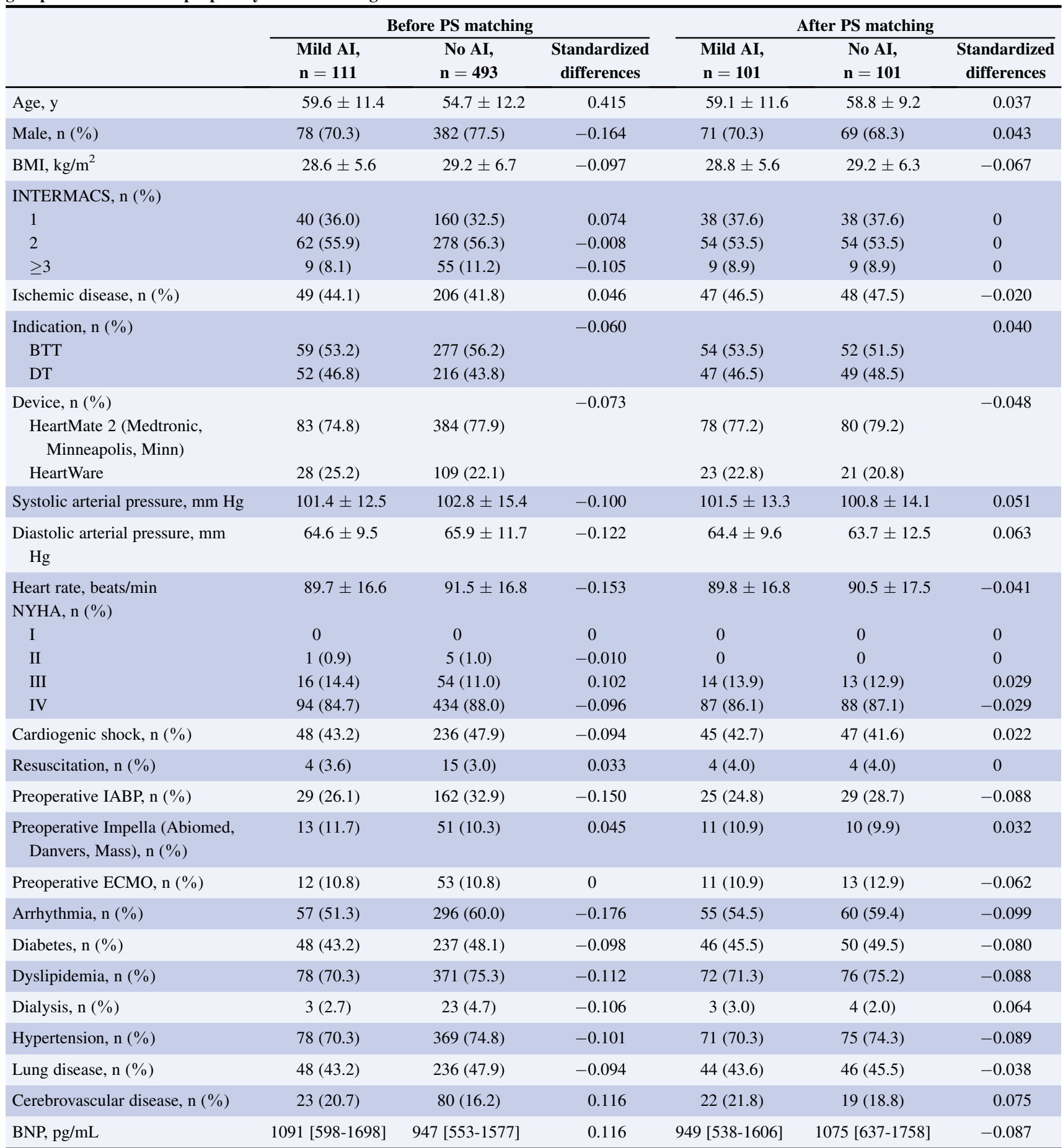

Continuous variables are presented as mean \pm standard deviation and categorical variables as number (\%). BNP is presented as median [25th-75th percentile]. PS, Propensity score; AI, aortic insufficiency; BMI, body mass index; INTERMACS, Interagency Registry for Mechanically Assisted Circulatory Support; BTT, bridge to transplantation; $D T$, destination therapy; NYHA, New York Heart Association; IABP, intra-aortic balloon pump; ECMO, extracorporeal membrane oxygenation; BNP, brain natriuretic peptide.

outcome variables such as post-LVAD TTE including progression of moderate or greater AI (primary outcome), MR, TR TAPSE, pulmonary artery pressure, BNP levels and NYHA functional status using the generalized linear mixed effect model. We used logit link ("binomial distribution") for binary outcomes including moderate or greater AI, MR, TR, and NYHA class III or IV, and used identity link ("Gaussian distribution") for continuous outcome variables including TAPSE, systolic pulmonary artery pressure, and BNP level. In the generalized mixed-effects model for 
TABLE 2. Comparisons of preoperative echocardiography, cardiac catheterization, and operative data between the mild aortic insufficiency and no aortic insufficiency groups, before and after propensity score matching

\begin{tabular}{|c|c|c|c|c|c|c|}
\hline & \multicolumn{3}{|c|}{ Before PS matching } & \multicolumn{3}{|c|}{ After PS matching } \\
\hline & $\begin{array}{c}\text { Mild AI, } \\
\mathrm{n}=\mathbf{1 1 1}\end{array}$ & $\begin{array}{c}\text { No AI, } \\
n=493\end{array}$ & $\begin{array}{c}\text { Standardized } \\
\text { differences }\end{array}$ & $\begin{array}{c}\text { Mild AI, } \\
\text { n=101 }\end{array}$ & $\begin{array}{l}\text { No AI, } \\
n=101\end{array}$ & $\begin{array}{c}\text { Standardized } \\
\text { differences }\end{array}$ \\
\hline \multicolumn{7}{|l|}{ Preoperative echocardiography } \\
\hline Aortic root diameter, $\mathrm{mm}$ & $32.5 \pm 3.6$ & $31.8 \pm 3.8$ & 0.189 & $32.5 \pm 3.7$ & $32.2 \pm 3.5$ & 0.083 \\
\hline Sclerotic aortic valve, n (\%) & $48(43.2)$ & $123(24.9)$ & 0.394 & $40(39.6)$ & $36(37.6)$ & 0.041 \\
\hline $\mathrm{LAD}, \mathrm{mm}$ & $48.9 \pm 7.5$ & $49.0 \pm 8.0$ & -0.013 & $48.8 \pm 7.6$ & $49.2 \pm 7.4$ & -0.053 \\
\hline LVEDD, mm & $68.7 \pm 8.9$ & $68.5 \pm 10.5$ & 0.021 & $68.9 \pm 9.0$ & $69.0 \pm 11.4$ & -0.010 \\
\hline LVDs, mm & $61.7 \pm 10.0$ & $61.3 \pm 11.6$ & 0.037 & $61.8 \pm 10.1$ & $61.7 \pm 11.9$ & 0.009 \\
\hline RVEDD, mm & $42.8 \pm 9.2$ & $42.5 \pm 9.3$ & 0.032 & $42.6 \pm 9.3$ & $42.5 \pm 9.5$ & 0.011 \\
\hline LVEF, \% & $18.0 \pm 7.0$ & $18.5 \pm 8.1$ & -0.066 & $18.1 \pm 7.2$ & $18.4 \pm 8.5$ & -0.038 \\
\hline $\mathrm{MR} \geq \bmod , \mathrm{n}(\%)$ & $67(60.4)$ & $256(51.9)$ & 0.172 & $62(61.4)$ & $60(59.4)$ & 0.041 \\
\hline TR $\geq \bmod , \mathrm{n}(\%)$ & $32(28.8)$ & $172(34.9)$ & -0.131 & $29(28.7)$ & $32(31.7)$ & -0.065 \\
\hline TAPSE, $\mathrm{mm}$ & $14.1 \pm 5.3$ & $13.9 \pm 5.5$ & 0.037 & $14.2 \pm 5.2$ & $14.1 \pm 5.6$ & 0.019 \\
\hline Systolic PA pressure, $\mathrm{mm} \mathrm{Hg}$ & $52.1 \pm 15.0$ & $48.8 \pm 12.1$ & 0.242 & $51.1 \pm 14.8$ & $51.4 \pm 11.5$ & -0.025 \\
\hline \multicolumn{7}{|l|}{ Cardiac catheterization } \\
\hline RA pressure, $\mathrm{mm} \mathrm{Hg}$ & $14.0 \pm 6.8$ & $14.9 \pm 7.0$ & -0.130 & $13.9 \pm 6.7$ & $14.5 \pm 7.3$ & -0.086 \\
\hline Mean PA pressure, $\mathrm{mm} \mathrm{Hg}$ & $40.0 \pm 10.0$ & $40.3 \pm 9.7$ & -0.037 & $39.6 \pm 10.2$ & $39.8 \pm 9.4$ & -0.020 \\
\hline Wedge pressure, $\mathrm{mm} \mathrm{Hg}$ & $26.6 \pm 8.1$ & $27.5 \pm 8.4$ & -0.109 & $26.6 \pm 8.2$ & $27.2 \pm 8.7$ & -0.071 \\
\hline PVR, Wood units & $4.2 \pm 2.2$ & $3.9 \pm 2.4$ & 0.130 & $4.1 \pm 2.1$ & $3.9 \pm 2.0$ & 0.098 \\
\hline $\mathrm{CI}, \mathrm{L} / \mathrm{min} / \mathrm{m}^{2}$ & $1.8 \pm 0.5$ & $1.8 \pm 0.5$ & 0 & $1.8 \pm 0.5$ & $1.8 \pm 0.4$ & 0 \\
\hline \multicolumn{7}{|l|}{ Operative data } \\
\hline \multicolumn{7}{|l|}{ Surgical approach, n (\%) } \\
\hline Full sternotomy & $100(90.1)$ & $464(94.1)$ & -0.149 & $93(92.1)$ & $94(93.1)$ & -0.038 \\
\hline Partial sternotomy & $6(5.4)$ & $17(3.4)$ & 0.098 & $4(3.0)$ & $4(3.0)$ & 0 \\
\hline Left thoracotomy & $5(4.5)$ & $12(2.4)$ & 0.115 & $4(2.0)$ & $3(1.0)$ & 0.054 \\
\hline CPB time, min & $77.8 \pm 37.1$ & $76.4 \pm 39.6$ & 0.053 & $76.9 \pm 34.9$ & $76.0 \pm 37.9$ & 0.025 \\
\hline MV procedure, n (\%) & $1(0.9)$ & $13(2.6)$ & -0.130 & $1(1.0)$ & $1(1.0)$ & 0 \\
\hline TV procedure, $\mathrm{n}(\%)$ & 14 (12.6) & 66 (13.4) & -0.024 & 13 (12.9) & 13 (12.9) & 0 \\
\hline
\end{tabular}

Continuous variables are shown as mean \pm standard deviation and categorical variables are shown as number (\%). $P S$, Propensity score; $A I$, aortic insufficiency; $L A D$, left atrial dimension; $L V E D D$, left ventricular end-diastolic dimension; $L V D s$, left ventricular end-systolic dimension; $R V E D D$, right ventricular end-diastolic dimension; $L V E F$, left ventricular ejection fraction; $M R$, mitral valve regurgitation; $\geq \bmod$, moderate or greater; $T R$, tricuspid valve regurgitation; TAPSE, tricuspid annular plane systolic excursion; $R A$, right atrium; $P A$, pulmonary artery; $P V R$, pulmonary vascular resistance; $C I$, cardiac index; $C P B$, cardiopulmonary bypass; $M V$, mitral valve; $T V$, tricuspid valve.

each outcome variable, we set matched-set id as the random effect term to model the potential correlation between matched subjects within each matching set, and we also modeled the serial correlation of repeated measurements from each study subject using the spatial power variance and covariance structure because of the unequal spacing of time intervals. Pre-LVAD severity and LVAD support duration were included in the generalized mixed-effects model as fixed effects.

Incidence of overall readmission and readmission caused by congestive heart failure (CHF) was analyzed by the Fine and Gray subdistribution hazard method with death after LVAD implant as competing risk and reported as a cumulative incidence curve. For the overall readmission analysis, all first readmissions due to any reasons were counted and plotted on cumulative incidence curves, and second or further readmissions were not included. In the analysis of CHF-related readmissions, first CHF-related readmissions were plotted and any other causes were not counted. Survival was analyzed by the Kaplan-Meier method, evaluating group comparisons with the stratified log-rank test. Drop-out and end of study period were regarded as censoring events. In the analysis of shortterm outcomes, McNemar's test was used for categorical variables, and Wilcoxon signed-rank test was used for continuous variables based on the propensity score-matched pair. In the analysis of the risk factors for post-LVAD moderate or greater AI in patients with pre-LVAD mild AI, variables with a $P$ value .05 or less in the univariate analysis and age and aortic valve nonopening were used in the multivariable analysis. Odds ratios (ORs) for progressing to moderate or greater AI were calculated with $95 \%$ confidence intervals (CIs).

\section{RESULTS \\ Demographic and Clinical Characteristics}

Pre-LVAD implantation demographic and clinical characteristics were compared on the basis of the standardized difference between all of the patients with mild AI $(n=111)$ and all of the patients with trace or no AI $(n=493)$ (Tables 1 and 2). After propensity score matching, there was no significant difference with |standardized difference| $<0.1$ between the mild AI $(\mathrm{n}=101)$ and the no AI $(\mathrm{n}=101)$ groups in any preoperative variable other than pre-LVAD AI grade (Tables 1 and 2). LVAD support time and pump speed were similar between 2 groups (Table E1). 
TABLE 3. Generalized linear mixed effect model analysis of pre-left ventricular assist device mild aortic insufficiency on post-left ventricular assist device echocardiogram parameters, brain natriuretic peptide, and New York Heart Association functional status

\begin{tabular}{lrrr}
\hline & Estimate & SE & $\boldsymbol{P}$ value \\
\hline Post-LVAD AI $\geq$ mod & & & \\
$\quad$ Mild AI & 2.03 & 0.36 & $<.01$ \\
LVAD support duration & 0.71 & 0.12 & $<.01$ \\
Post-LVAD MR $\geq$ mod & & & \\
$\quad$ Mild AI & 0.95 & 0.26 & $<.01$ \\
LVAD support duration & 0.51 & 0.11 & $<.01$ \\
Post-LVAD TR $\geq$ mod & & & \\
Mild AI & 0.74 & 0.23 & $<.01$ \\
LVAD support duration & 0.09 & 0.09 & .33 \\
Post-LVAD TAPSE & & & \\
Mild AI & -3.08 & 0.54 & $<.01$ \\
LVAD support duration & -0.30 & 0.20 & .14 \\
\hline Post-LVAD systolic PA pressure & & & \\
Mild AI & 5.94 & 0.84 & $<.01$ \\
LVAD support duration & 0.06 & 0.31 & .85 \\
Post-LVAD BNP & & & \\
Mild AI & 364.27 & 76.03 & $<.01$ \\
LVAD support duration & 87.36 & 28.31 & $<.01$ \\
\hline Post-LVAD NYHA class III or greater & & & \\
Mild AI & 1.19 & 0.25 & $<.01$ \\
LVAD support duration & 0.13 & 0.09 & .13 \\
\hline
\end{tabular}

The generalized linear mixed model included all post-LVAD echocardiogram, BNP and NYHA data with sample size of 281 in the Mild AI group and 241 in the No AI group. BNP and NYHA were collected at the same time as the echocardiogram measurements. $S E$, Standard error; $L V A D$, left ventricular assist device; $A I$, aortic insufficiency; $\geq$ mod, moderate or greater; $M R$, mitral valve regurgitation; $T R$, tricuspid valve regurgitation; $T A P S E$, tricuspid annular plane systolic excursion; $P A$, pulmonary artery; $B N P$, brain natriuretic peptide; NYHA, New York Heart Association.

\section{Primary Outcome: Progression of Aortic Insufficiency to Moderate or Greater After Left Ventricular Assist Device Implantation}

Forty-four patients $(43.6 \%)$ in the mild AI group progressed to moderate or greater $\mathrm{AI}$, and 9 patients $(8.9 \%)$ in the no AI group developed moderate or greater AI with the mean total follow-up period until death or censoring event of $2.3 \pm 1.8$ years and $2.1 \pm 1.8$ years, respectively $(P=.32)$. The generalized linear mixed model analyses demonstrated that both pre-LVAD mild AI $(P<.01)$ and longer LVAD support duration $(P<.01)$ were significant risk factors for the incidence of post-LVAD moderate or greater AI (Table 3 and Figure 2).

\section{Secondary Outcomes: Survival, New York Heart Association Functional Class, and Readmission Rate}

The Kaplan-Meier survival analysis indicated that survival was similar in both groups $(P=.58)$ : $74 \%$ at 1 year, $64 \%$ at 2 years, and $59 \%$ at 3 years in the mild AI group, and $71 \%$ at 1 year, $69 \%$ at 2 years, and $63 \%$ at

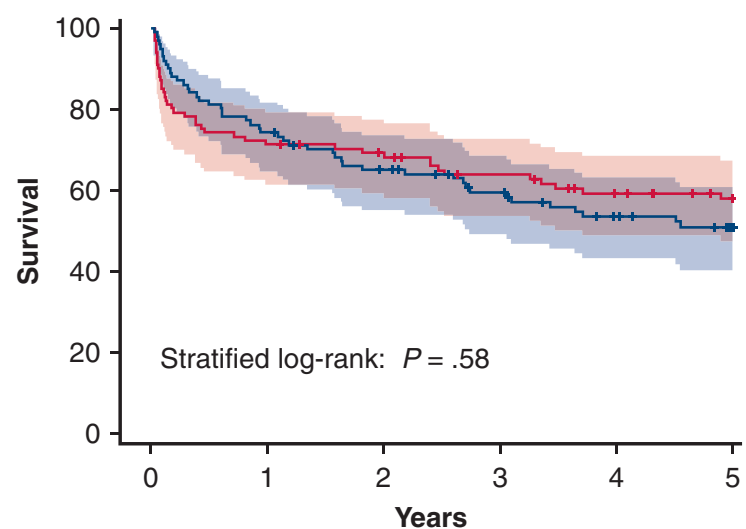

Patients at risk

$\begin{array}{llllll}\text { Mild Al } 101 & 75 & 63 & 52 & 42 & 34\end{array}$

$\begin{array}{lllllll}\text { No Al } & 101 & 72 & 67 & 58 & 49 & 42\end{array}$

- Mild Al Mild Al-95\% Cl + Censored

- No Al No Al-95\% Cl

FIGURE 3. Kaplan-Meier survival curve for the mild AI $(n=101)$ and no AI $(n=101)$ groups. The stratified log-rank test was used for estimating survival difference between propensity score-matched groups. Drop-out and end of study period were regarded as censoring events. The $95 \% \mathrm{CI}$ bands are shown with the survival curve. AI, Aortic insufficiency; $C I$, confidence interval.

3 years in the no AI group (Figure 3). In the analysis by generalized linear mixed model, mild $\mathrm{AI}$ at the time of LVAD implant was also associated with worse NYHA functional status $(P<.01$, Table 3 and Figure 2$)$. Although the overall readmission rate was similar in both groups (hazard ratio, $1.23 ; 95 \% \mathrm{CI}, 0.91-1.49 ; P=.24$, Figure $4, A$ ), the readmission rate caused by $\mathrm{CHF}$ was significantly higher in the mild AI group (hazard ratio, 2.62; 95\% CI, 1.424.69; $P<.01$, Figure $4, B$ ).

\section{Short-Term Outcomes}

For the short-term outcomes, the mild AI group tended to have lower 30 -day mortality (mild AI vs no AI; $5.9 \%$ vs $10.9 \%, P=.14)$, lower incidence of right ventricular (RV) failure ( $14.9 \%$ vs $19.8 \%, P=.47)$, stroke $(5.0 \%$ vs $10.9 \%, P=.18)$, gastrointestinal bleeding $(19.8 \%$ vs $25.7 \%, P=.44)$, and bleeding requiring reoperation $(9.9 \%$ vs $13.9 \%, P=.52)$, although there was no significant difference between the 2 groups. Additionally, there was no significant difference in hospital stay or other complications, such as renal replacement therapy, surgical site infection, and sepsis between the 2 groups (Table 4).

\section{Post-Left Ventricular Assist Device} Echocardiographic Parameters and Brain Natriuretic Peptide Levels

The mean follow-up periods for the serial TTE after LVAD implantation were similar for the mild AI and no 


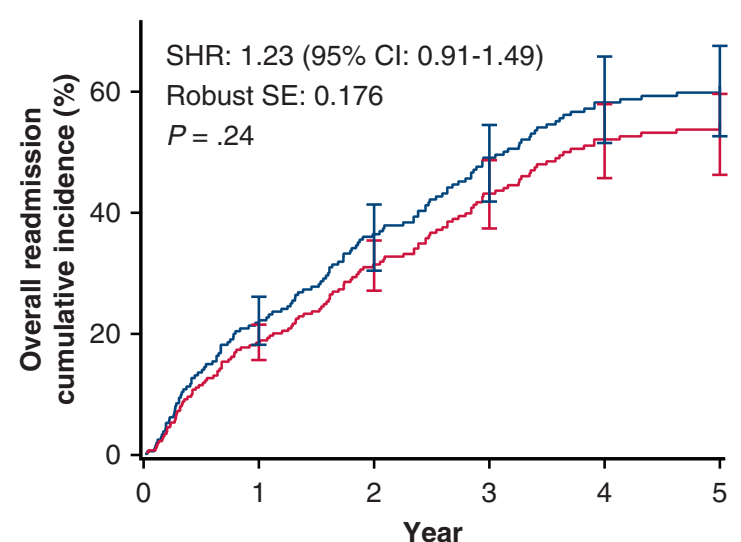

Patients at risk

$\begin{array}{lllllll}\text { - Mild Al } & 101 & 67 & 44 & 27 & 16 & 13 \\ \text { No Al } & 101 & 54 & 38 & 24 & 14 & 11\end{array}$

A

FIGURE 4. A Cumulative incidence rate of overall readmission for the mild AI $g$ r

up (blue, $\mathrm{n}=101)$ and the no AI group (red, $\mathrm{n}=101)$. B, Cumulative incidence rate of readmission caused by $\mathrm{CHF}$ for the mild AI group (blue, $\mathrm{n}=101$ ) and the no AI group (red, $\mathrm{n}=101)$. Cumulative incidence curves with 95\% CI bars were analyzed by the Fine and Gray subdistribution hazard method with death as competing risk. For overall readmission analysis, all first readmissions due to any reasons were counted and plotted on cumulative incidence curves, and second or further readmissions were not included. In the analysis of CHF-related readmissions, any other causes were not counted, but first CHF-related readmissions were plotted. Drop-out and end of study period were censored. The robust standard errors were used for estimating the difference in cumulative incidence of readmission between propensity scorematched groups. SHR, Subdistribution hazard ratio; $C I$, confidence interval; $S E$, standard error; $A I$, aortic insufficiency; $C H F$, congestive heart failure.

AI groups $(0.8 \pm 1.3$ vs $0.7 \pm 1.1$ years, $P=.20)$. Also, there was no significant difference in time interval $(10.9 \pm 3.3$ vs $10.7 \pm 3.2$ months, $P=.46)$ and frequency

TABLE 4. Short-term outcomes for the mild aortic insufficiency and no aortic insufficiency groups

\begin{tabular}{lccc}
\hline & $\begin{array}{c}\text { Mild AI, } \\
\mathbf{n = 1 0 1}\end{array}$ & $\begin{array}{c}\text { No AI, } \\
\mathbf{n}=\mathbf{1 0 1}\end{array}$ & $\boldsymbol{P}$ value \\
\hline Hospital stay, d & $27.3 \pm 20.8$ & $26.8 \pm 22.2$ & .87 \\
Complications within 30 d, & & & \\
$\quad$ n (\%) & & & \\
Mortality & $6(5.9)$ & $11(10.9)$ & .14 \\
RV failure & $15(14.9)$ & $20(19.8)$ & .47 \\
$\quad$ Unplanned RVAD & $10(9.9)$ & $7(6.9)$ & .58 \\
$\quad$ Inotropic use over 2 wk & $5(5.0)$ & $13(12.9)$ & .10 \\
$\quad$ after LVAD & & & \\
Stroke & $5(5.0)$ & $11(10.9)$ & .18 \\
Renal replacement therapy & $9(8.9)$ & $11(10.9)$ & .69 \\
GI bleeding & $20(19.8)$ & $26(25.7)$ & .44 \\
Bleeding requiring & $10(9.9)$ & $14(13.9)$ & .52 \\
$\quad$ reoperation & & & \\
Surgical site infection & $6(5.9)$ & $6(5.9)$ & .99 \\
Sepsis & $11(10.9)$ & $11(10.9)$ & .99 \\
\hline
\end{tabular}

McNemar's test was used for categorical variables, and Wilcoxon signed rank test was used for continuous variables in propensity-score matched pair. Continuous variables are shown as mean \pm standard deviation, and categorical variables are shown as number (\%). $A I$, Aortic insufficiency; $R V$, right ventricular; $R V A D$, right ventricular assist device; $L V A D$, left ventricular assist device; $G I$, gastrointestinal.
$(2.8 \pm 1.4$ vs $2.4 \pm 1.2$ measurements/patient, $P=.06)$ of echocardiogram measurements between the 2 groups (Table E2). Analysis using generalized linear mixed model demonstrated that pre-LVAD mild AI was associated with not only higher incidence of post-LVAD moderate or greater MR $(P<.01)$ and post-LVAD moderate or greater TR $(P<.01)$, but also worse TAPSE $(P<.01)$ and higher systolic PA pressure $(P<.01)$ after LVAD implantation (Table 3 and Figure 2). Furthermore, post-LVAD BNP levels were significantly higher in the mild AI group $(P<.01)$ (Table 3$)$. On the other hand, LVAD support duration was not associated with any response variables other than progression of moderate or greater AI $(P<.01)$, MR $(P<.01)$, and BNP levels $(P<.01$, Table 3 and Figure 2$)$.

\section{Risk Factor Analysis for the Post-Left Ventricular Assist Device Moderate or Greater Aortic Insufficiency in Patients With Pre-Left Ventricular Assist Device Mild Aortic Insufficiency (Table E3)}

Table E3 summarizes the results of the risk factor analysis for progression of AI to moderate or greater. Overall, 111 patients had mild AI before implantation of the LVAD. Of these, $48(43.2 \%)$ developed moderate or greater AI during the 2.5-year average follow-up period. The univariate analyses identified the following significant predictors: DT $(P<.01)$, implantation with a HeartMate 2 device $(P=.02)$, smaller aortic root diameter $(P=.02)$, and longer 
LVAD duration $(P<.01)$. In the multivariable analysis including age, nonopening aortic valve, and variables that had a $P$ value .05 or less in the univariate analysis, DT status (OR, 3.54; 95\% CI, 1.46-8.58; $P<.01$ ) and longer LVAD duration (OR, $1.51 ; 95 \% \mathrm{CI}, 1.21-1.88 ; P<.01)$ were significant risk factors for progression to moderate or greater AI for patients with pre-LVAD mild AI.

\section{DISCUSSION}

The primary finding of this retrospective study of a propensity-matched cohort was that uncorrected mild AI at the time of LVAD implant and LVAD support duration were associated with a significantly higher risk of postLVAD moderate or greater AI compared with trace or no AI. Previous nonrandomized and nonpropensity scorematched studies reported even worse AI progression in patients without $\mathrm{AI}$ at baseline. ${ }^{4-6}$ However, there are no clear guidelines regarding the approach for mild AI at baseline with LVAD implantation. ${ }^{15}$ Our findings shed light on this condition and suggest the need for further investigation and the development of better treatment strategies to improve the quality of life and reduce readmissions in the long-term management of these patients.

\section{Survival and Functional Status}

The 2 propensity score-matched groups in this study, with mild AI and without AI, had similar survival. Toda and colleagues ${ }^{18}$ reported that the development of AI within 1 year after LVAD implantation reduced survival in 43 patients with paracorporeal pulsatile devices compared with patients who did not develop AI. Conversely, other studies with implantable continuous-flow LVADs have suggested that post-LVAD moderate or greater AI was not associated with decreased survival. ${ }^{6-10,13}$ The results of those studies were consistent with our findings that mild AI before implantation did not result in worse survival after implantation compared with patients with no or trace AI, even though many of the patients with mild AI experienced deterioration of their condition.

In a study of 52 patients with continuous-flow LVAD implants, Imamura and colleagues ${ }^{13}$ found that post-LVAD AI was associated with lower exercise capacity and higher readmission rates compared with no AI. Likewise, our study showed that the higher incidence of moderate or greater AI in patients with pre-LVAD mild AI was significantly associated with worse NYHA functional class and higher rates of readmission because of CHF. Furthermore, the independent risk factors for the progression of AI were an indication for DT and longer LVAD support (Table E3). The recent modification to the organ allocation system in the United States has resulted in a larger proportion of patients receiving LVAD implants as DT. ${ }^{19}$ As a result, patients can be expected to continue with the LVAD devices for a longer period, even if they subsequently become eligible for heart transplant. Therefore, a surgical intervention for pre-LVAD mild AI needs to be positively considered, especially for patients who will stay on the LVAD for a long period of time, irrespective of BTT or DT indication, to experience better functional status.

\section{Surgical Intervention for Pre-Left Ventricular Assist Device Aortic Insufficiency}

It remains unclear whether concomitant aortic valve procedures for patients with pre-LVAD mild AI are beneficial for their functional status. A large observational study based on Interagency Registry for Mechanically Assisted Circulatory Support data compared the incidence of AI and survival after LVAD implantation between patients who underwent no concomitant aortic valve procedure $(\mathrm{n}=5039)$ and those who underwent aortic valve closure $(n=125)$, aortic valve repair with central suture $(n=95)$, and aortic valve replacement $(\mathrm{n}=85) .{ }^{20}$ In this study, aortic valve closure was associated with the highest mortality rates, and aortic valve repair was associated with the highest incidence of AI progression. Fukuhara and colleagues ${ }^{21}$ reported that concomitant aortic valve repair for patients with mild AI pre-LVAD reduced the incidence of moderate or greater AI after the LVAD implantation, although the procedure had no significant impact on survival when compared with the patients with uncorrected mild AI. In this study, post-LVAD functional data were not reported..$^{21}$ In our study, the data suggested that unrepaired mild AI resulted in significantly worse functional status post-LVAD. Considering this result, we now more carefully assess the AI grade and proactively perform concomitant aortic valve central suture (Park stitch) for mild or greater AI. Further analysis is warranted to evaluate the functional and survival benefits of concomitant aortic valve procedure for patients with mild $\mathrm{AI}$ at the time of LVAD implant.

\section{Intervention for Post-Left Ventricular Assist Device Aortic Insufficiency}

In this study, $44 \%$ of the patients in the mild AI group developed moderate or greater AI, and interestingly, 9\% of patients in the no AI group developed de novo AI during the 2-year follow-up term. Some of these patients who developed severe heart failure underwent transcatheter aortic valve replacement (TAVR) or surgical aortic valve repair with Park stitch, which resulted in sufficient midterm outcomes. Some previous case reports also showed excellent outcomes of TAVR for patients with post-LVAD AI. ${ }^{22,23}$ This might be preferred for someone who is a heart transplant candidate to avoid further surgical interventions before complicated heart transplant with LVAD explant surgery, but the decision-making process can be complicated for those who are not adequate candidates for TAVR based on the etiology of AI, aortic annular size, and degree of calcification. Further investigations are warranted regarding 
TAVR versus surgical repair as well as the timing of the intervention for de novo AI and worsening significant $\mathrm{AI}$ after LVAD implant.

\section{Effects of Aortic Insufficiency Progression on Mitral Regurgitation, Tricuspid Regurgitation, and Right Ventricular Function}

In approximately 2 years of follow-up after LVAD implantation, the patients with mild AI before implantation had significantly worse MR and TR grades and worse RV function with reduced TAPSE than the patients who had no or trace AI. The effects of AI on MR, TR, and RV function after LVAD implantation have not been well investigated. According to the study by Cowger and colleagues ${ }^{8}$ of 166 patients who received continuous-flow LVAD implants who had no AI pre-LVAD, there was no significant association between post-LVAD moderate or greater AI and worse MR or RV function. Conversely, our study suggested that mild AI pre-LVAD may lead to worse MR, worse TR, and worse RV function compared with the patients with no AI. It is highly likely that the NYHA functional capacity of the mild AI group was adversely affected by their worse MR, TR, and RV function. Furthermore, it is also possible that echocardiographic evaluation of $\mathrm{AI}$ grade may underestimate the degree of $\mathrm{AI}$ in LVAD patients compared with non-LVAD patients with significant AI. The AI grade for LVAD patients has been assessed using the traditional method for non-LVAD patients, such as effective regurgitant orifice area or regurgitant jet. For patients with LVAD, AI could occur during a longer period in a cardiac cycle throughout the diastolic phase or even part of the isovolumetric phase. Precise echocardiographic analyses are desired to understand the significance of AI and its adverse effect on functional capacity in patients with LVAD.

\section{Study Limitations}

This retrospective study has some limitations. First, we used propensity score matching to adjust the patient populations for the groups with pre-LVAD mild AI and pre-LVAD no or trace AI. However, this reduced the number of patients in the study. Second, the study included patients who underwent LVAD surgery performed by multiple surgeons using different surgical strategies. Third, some post-LVAD factors such as medications, arterial pressure, and total aortic flow, which may have affected hemodynamics, were not included in the analysis. Fourth, only patients who received HeartMate 2 and HeartWare implants were enrolled in this study, so no conclusions could be made about the possible effects of AI with any other devices. Fifth, the follow-up period is different in each patient because of the retrospective review. As a result, a mixed-effect model was necessary to appropriately assess the outcome of each patient group. Additionally, we focused on the freedom from readmission related to CHF rather than severity of CHF with multiple readmissions. Therefore, second or further readmission events with $\mathrm{CHF}$ were not collected to run a repeated events model for this study. Finally, no conclusions can be drawn regarding the effects of performing a concomitant aortic valve procedure at the time of LVAD implantation for patients with mild AI, because patients who underwent this procedure were excluded from the study.

\section{CONCLUSIONS}

Uncorrected mild AI at the time of LVAD implantation was associated with a higher risk of progression to moderate or greater AI and worse NYHA functional class and more CHF-related readmissions in the midterm after LVAD implantation compared with no or trace AI. Indication for DT and LVAD support duration were independent risk factors for progression to moderate or greater $\mathrm{AI}$ in patients with pre-LVAD mild AI. Concomitant aortic valve procedure may need to be considered for mild or greater $\mathrm{AI}$ at the time of LVAD implant to prevent future development of moderate or greater AI and deterioration of functional capacity. Further investigations of the efficacy and safety of surgical treatment for mild AI at the time of LVAD implant are warranted. This may help improve the quality of life in patients with DT and BTT with the expected longer LVAD management due to the new US heart allocation system.

\section{Webcast \\ You can watch a Webcast of this AATS meeting presenta- tion by going to: https://aats.blob.core.windows.net/ media/19\%20AM/Sunday_May5/206AC/206AC/S54\%20- \%20Implantable \%20Ventricular\%20Assist \%20Devices/ S54_7_webcast_025634896.mp4.}

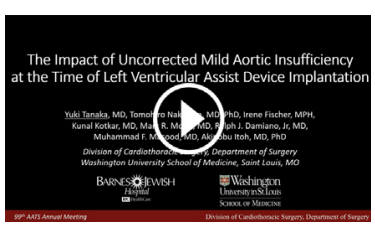

\section{Conflict of Interest Statement}

Dr Itoh: surgical advisory and speaker honorarium for $\mathrm{Ab}-$ bott, Medtronic, and Abiomed. Dr Damiano: consultant for Medtronic and speaker honorarium for Atricure, LivaNova, and Edwards. All other authors reported no conflicts of interest.

The Journal policy requires editors and reviewers to disclose conflicts of interest and to decline handling or reviewing manuscripts for which they may have a conflict 
of interest. The editors and reviewers of this article have no conflicts of interest.

\section{References}

1. Miller LW, Pagani FD, Russell SD, John R, Boyle AJ, Aaronson KD, et al. Use of a continuous-flow device in patients awaiting heart transplantation. $N$ Engl $J$ Med. 2007:357:885-96.

2. Rose EA, Gelijns AC, Moskowitz AJ, Heitjan DF, Stevenson LW, Dembitsky W, et al. Long-term mechanical left ventricular assistance for end-stage heart failure. N Engl J Med. 2001;345:1435-43.

3. Kirklin JK, Naftel DC, Pagani FD, Kormos RL, Stevenson LW, Blume ED, et al. Seventh INTERMACS annual report: 15,000 patients and counting. J Heart Lung Transplant. 2015;34:1495-504.

4. Cowger JA, Pagani FD, Haft JW, Romano MA, Aaronson KD, Kolias T. The development of aortic insufficiency in LVAD supported patients. Circ Heart Fail. 2010;3:668-74.

5. Pak SW, Uriel N, Takayama H, Bejar D, Gonzalez-Costello J, Thomas SS, et al. Prevalence of de novo aortic insufficiency during long term support with left ventricular assist devices. J Heart Lung Transplant. 2010;29:1172-6.

6. Aggarwal A, Raghuvir R, Eryazici P, Macaluso G, Sharma P, Blair C, et al. The development of aortic insufficiency in continuous flow left ventricular assist device supported patients. Ann Thorac Surg. 2013;95:493-8.

7. Jorde UP, Uriel N, Nahumi N, Bejar D, Gonzalez-Costello J, Thomas SS, et al. Prevalence, significance, and management of aortic insufficiency in continuous flow left ventricular assist device recipients. Circ Heart Fail. 2014;7:310-9.

8. Cowger JA, Aaronson KD, Romano MA, Haft J, Pagani FD. Consequences of aortic insufficiency during long-term axial continuous-flow left ventricular assist device support. J Heart Lung Transplant. 2014;33:1233-40.

9. Rajagopal K, Daneshmand MA, Patel CB, Ganapathi AM, Schechter MA, Rogers JG, et al. Natural history and clinical effect of aortic valve regurgitation after left ventricular assist device implantation. J Thorac Cardiovasc Surg. 2013; 145:1373-9.

10. Holley CT, Fitzpatrick M, Roy SS, Alraies MC, Cogswell R, Souslian L, et al. Aortic insufficiency in continuous-flow left ventricular assist device support patients is common but does not impact long-term mortality. J Heart Lung Transplant. 2017;36:91-6.

11. Hatano M, Kinugawa K, Shiga T, Kato N, Endo M, Hisagi M, et al. Less frequent opening of the aortic valve and a continuous flow pump are risk factors for postoperative onset of aortic insufficiency in patients with a left ventricular assist device. Circ J. 2011;75:1147-55.

12. Imamura T, Kinugawa K. Preoperative prediction of aortic insufficiency during ventricular assist device treatment. Int Heart J. 2016;57:3-10.

13. Imamura T, Kinugawa K, Fujino T, Inaba T, Maki H, Hatano M, et al. Aortic insufficiency in patients with sustained left ventricular systolic dysfunction after axial flow assist device implantation. Circ J. 2015;79:104-11.

14. Iizuka K, Nishinaka T, Akiyama D, Sumikura H, Mizuno T, Tsukiya T, et al. The angle of the outflow graft to the aorta can affect recirculation due to aortic insufficiency under left ventricular assist device support. J Artif Organs. 2018:21:399-404.

15. Feldman D, Pamboukian SV, Teuteberg JJ, Birks E, Lietz K, Moore SA, et al. The 2013 International Society for Heart and Lung Transplantation guidelines for mechanical circulatory support: executive summary. J Heart Lung Transplant. 2013; 32:157-87.

16. Zoghbi WA, Enriquez-Sarano M, Foster E, Grayburn PA, Kraft CD, Levine RA, et al. Recommendations for evaluation of the severity of native valvular regurgitation with two-dimensional and Doppler echocardiography. J Am Soc Echocardiogr. 2003; 16:777-802.

17. Rosenbaum PR, Rubin DB. The central role of the propensity-score in observational studies for causal effects. Biometrika. 1983;70:41-55.

18. Toda K, Fujita T, Domae K, Shimahara Y, Kobayashi J, Nakatani T. Late aortic insufficiency related to poor prognosis during left ventricular assist device support. Ann Thorac Surg. 2011;92:929-34.

19. Kormos RL, Cowger J, Pagani FD, Teuteberg JJ, Goldstein DJ, Jacobs JP, et al. The Society of Thoracic Surgeons intermacs database annual report: evolving indications, outcomes, and scientific partnerships. J Heart Lung Transplant. 2019; 38:114-26.

20. Robertson JO, Naftel DC, Myers SL, Prasad S, Mertz GD, Itoh A, et al. Concomitant aortic valve procedures in patients undergoing implantation of continuous- flow left ventricular assist devices: an INTERMACS database analysis. J Heart Lung Transplant. 2015:34:797-805.

21. Fukuhara S, Ikegami H, Polanco AR, Song JJ, Han J, Takeda K, et al. Concomitant repair for mild aortic insufficiency and continuous-flow left ventricular assist devices. Eur J Cardiothorac Surg. 2017;52:1062-8.

22. Kozarek K, Minhaj MM, Chaney MA, D'Ancona G, Pasic M, Carrel T, et al. Transcatheter aortic valve replacement for left ventricular assist deviceinduced aortic insufficiency. J Cardiothorac and Valve Anesth. 2018;32:1982-90.

23. Atkins Z, Hashmi ZA, Ganapathi AM, Harrison JK, Hughes GC, Rogers JG, et al Surgical correction of aortic valve insufficiency after left ventricular assist device implantation. J Thorac Cardiovasc Surg. 2013;146:1247-52.

Key Words: left ventricular assist device, aortic valve insufficiency, functional status, heart failure

\section{Discussion}

\section{Presenter: Dr Yuki Tanaka}

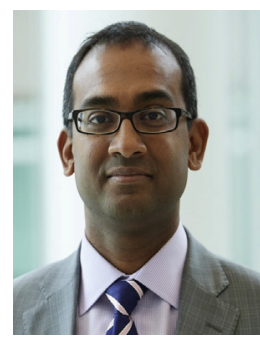

Dr Pavan Atluri (Philadelphia, Pa). As a comment, as a field, I think we greatly underestimate the value of valvular regurgitation on physiology, and in particular in this study you clearly demonstrate a negative physiologic impact of uncorrected mild AI at the time of LVAD implant. Your study nicely highlights the importance of a further focus on the management of $\mathrm{AI}$, and as we continue to see improvements in survival that currently are on par with heart transplant, or are approaching heart transplant, we will need to as a field continue to focus on adverse events if we are to continue to push the therapy forward. A few additional points that I noted from your data. First, the mild AI cohort, I was interested to see had significantly elevated right atrial pressures, pulmonary arterial pressures, as well as wedge pressures, which demonstrates a clear additive stress that may impact $\mathrm{RV}$ performance. Second, I was interested to see that preoperative aortic root dimension was not a correlative factor with the development of AI.

Third, another observation was that I was interested in was the low rate of progression of $\mathrm{AI}$ in the no AI cohort, whereas traditional teaching has indicated a $30 \%$ rate of formation of de novo AI. So this really raises the question that maybe the indicators for AI and de novo AI actually exist at the time of implant. Suggesting that potentially a more aggressive surgical addressing of $\mathrm{AI}$ at $1+$ or more, rather than the current guidelines of $2+$ may be indicated. Did you find a correlation with delayed RV failure in the cohort that had moderate AI? Would you then suggest that surgeons intervene earlier upon the recognition of moderate AI? Second, do you think we are underestimating AI by 
traditional metrics, most notably effect of regurgitant orifice with a regurgitant jet? And the least scientific of which is qualitative visual assessment. When do you recommend that we intervene on de novo AI post-LVAD, because I frankly think we are intervening too late.

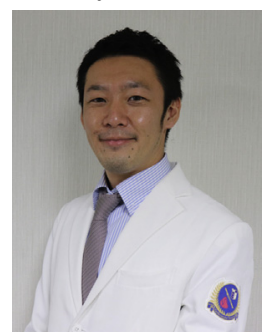

Dr Yuki Tanaka (St Louis, Mo). We didn't include the late RV failure analyses in this presentation, but those are in the paper we submitted. In the follow-up cardiogram, we observed significantly worse TAPSE, more MR and TR in the moderate AI group compared with no AI group in 2.5 years of follow-up. In other words, our study demonstrated that pre-LVAD mild AI was associated with progression of MR, TR, and RV dysfunction after the implant. In suggestions about evaluation of AI severity, I absolutely agree with you. The assessment about AI has been difficult in patients with LVAD, and there is no specific criteria for LVAD recipients who show $\mathrm{AI}$ for the entire cardiac cycle. We are going to find some answers soon. We are working on mock loop LVAD model with the mild AI before and after LVAD by measuring the systemic flow, LVAD flow, and transaortic valve flow. We should consider AI treatment in patients who have become class III or IV with no exercise tolerance even though patients are treated with all the afterload reduction medication. Surgical repair and transcatheter AVR are options, but earlier treatment is better, especially if you won't get them ready for transplant. So far, we treated only 1 patient with TAVR (a 46-year-old woman and 4 surgical repairs with Park stitch). All went well, and NYHA class was improved from IV to I or II.

Dr Atluri. Great, thank you, and I look forward to seeing your paper in press.

Unidentified Speaker. My question for you is how should we address AI and post-LVAD? Are you doing TAVRs, are you taking them back for valve replacement, or are you doing a Park stitch?

Dr Tanaka. In our institution, moderate or greater AI is usually repaired at the time of the LVAD implant. Aortic valve central suture is performed in almost patients with moderate to great AI. However, AVR using tissue valve is selected in patients with mechanical valve. In mild AI, making a decision of concomitant aortic valve procedure was done based on tolerance to surgery. Post-LVAD de novo AI may need to be treated when NYHA functional class progresses to class IIIb or IV. We usually select Park stitch or TAVR for post-LVAD significant AI with deterioration of functional status at this point. 
TABLE E1. Comparison of outcomes between the mild aortic insufficiency group and no aortic insufficiency groups

\begin{tabular}{lccc}
\hline & Mild AI, $\mathbf{n}=\mathbf{1 0 1}$ & No AI, $\mathbf{n}=\mathbf{1 0 1}$ & $\boldsymbol{P}$ value \\
\hline LVAD pump speed, rpm & & & \\
$\quad$ HeartMate 2 & $9190.6 \pm 608.6$ & $9251.5 \pm 234.5$ & .87 \\
$\quad$ HeartWare & $2729.6 \pm 159.1$ & $2681.1 \pm 177.6$ & .88 \\
LVAD duration, $y$ & $2.3 \pm 1.8$ & $2.1 \pm 1.8$ & .36 \\
Aortic valve nonopening, $\mathrm{n}(\%)$ & $51(50.5)$ & $40(39.6)$ & .15 \\
Heart transplant, $\mathrm{n}(\%)$ & $24(23.8)$ & $29(28.7)$ & .67 \\
\hline
\end{tabular}

McNemar's test was used for categorical variables, and Wilcoxon signed-rank test was used for continuous variables in the propensity score-matched groups. Continuous variables are shown as mean \pm standard deviation, and categorical variables are shown as number $(\%)$. AI, Aortic insufficiency; $L V A D$, left ventricular assist device.

TABLE E2. Post-left ventricular assist device echocardiogram data over time for the mild aortic insufficiency and the no aortic insufficiency groups

\begin{tabular}{|c|c|c|c|c|c|c|}
\hline & \multicolumn{3}{|c|}{ 0-3 mo } & \multicolumn{3}{|c|}{ 3-12 mo } \\
\hline & $\overline{\text { Mild AI, }} \mathbf{n}=101$ & No $A I, n=101$ & $P$ value & Mild AI, $n=82$ & No $A I, n=72$ & $P$ value \\
\hline Timing of TEE, mo & $1.3 \pm 0.8$ & $1.3 \pm 0.8$ & .99 & $6.7 \pm 3.2$ & $6.8 \pm 3.3$ & .89 \\
\hline Aortic root diameter, $\mathrm{mm}$ & $33.6 \pm 3.4$ & $32.6 \pm 4.0$ & .25 & $34.8 \pm 3.2$ & $33.6 \pm 3.6$ & .03 \\
\hline $\mathrm{LAD}, \mathrm{mm}$ & $43.9 \pm 8.6$ & $43.7 \pm 7.6$ & .88 & $46.1 \pm 6.7$ & $42.2 \pm 6.7$ & $<.01$ \\
\hline LVEDD, mm & $57.1 \pm 11.7$ & $55.8 \pm 12.8$ & .45 & $59.6 \pm 12.1$ & $57.4 \pm 15.7$ & .34 \\
\hline LVDs, mm & $50.6 \pm 12.4$ & $49.4 \pm 13.8$ & .51 & $52.9 \pm 13.6$ & $50.5 \pm 15.5$ & .32 \\
\hline RVEDD, mm & $41.5 \pm 9.6$ & $40.4 \pm 10.7$ & .46 & $46.0 \pm 11.7$ & $40.7 \pm 9.1$ & $<.01$ \\
\hline LVEF, mm & $19.9 \pm 8.5$ & $20.0 \pm 8.2$ & .62 & $21.0 \pm 9.7$ & $21.0 \pm 9.2$ & .99 \\
\hline $\mathrm{AI} \geq \bmod , \mathrm{n}(\%)$ & $2(2.0)$ & 0 & .50 & $25(30.5)$ & $5(6.9)$ & $<.01$ \\
\hline MR $\geq \bmod , \mathrm{n}(\%)$ & $15(14.9)$ & $15(14.9)$ & .99 & $24(29.3)$ & $9(12.5)$ & .01 \\
\hline $\mathrm{TR} \geq \bmod , \mathrm{n}(\%)$ & $26(25.7)$ & $22(21.8)$ & .51 & $24(29.3)$ & $10(13.9)$ & .02 \\
\hline TAPSE, mm & $13.7 \pm 5.8$ & $14.1 \pm 6.1$ & .59 & $12.0 \pm 5.4$ & $15.0 \pm 5.7$ & $<.01$ \\
\hline \multirow[t]{3}{*}{ Systolic PA pressure, $\mathrm{mm} \mathrm{Hg}$} & $32.3 \pm 9.2$ & $30.5 \pm 9.2$ & .14 & $31.7 \pm 9.1$ & $29.0 \pm 8.0$ & .06 \\
\hline & \multicolumn{3}{|c|}{ 12-24 mo } & \multicolumn{3}{|c|}{$>24$ mo } \\
\hline & Mild AI, $n=59$ & No $A I, n=48$ & $P$ value & Mild AI, n = 39 & No $A I, n=20$ & $P$ value \\
\hline Timing of TEE, mo & $16.8 \pm 4.4$ & $17.0 \pm 4.8$ & .76 & $32.5 \pm 5.0$ & $33.2 \pm 4.4$ & .58 \\
\hline Aortic root diameter, mm & $34.8 \pm 3.3$ & $33.5 \pm 3.7$ & .02 & $35.1 \pm 3.5$ & $34.9 \pm 2.8$ & .84 \\
\hline $\mathrm{LAD}, \mathrm{mm}$ & $45.7 \pm 7.2$ & $42.3 \pm 6.7$ & $<.01$ & $45.8 \pm 6.4$ & $44.2 \pm 6.5$ & .36 \\
\hline LVEDD, mm & $59.8 \pm 12.4$ & $57.4 \pm 16.1$ & .31 & $59.3 \pm 13.1$ & $53.5 \pm 17.9$ & .17 \\
\hline LVDs, mm & $53.4 \pm 13.6$ & $50.6 \pm 15.8$ & .24 & $52.7 \pm 14.9$ & $47.7 \pm 18.1$ & .27 \\
\hline RVEDD, mm & $45.5 \pm 11.3$ & $40.3 \pm 9.2$ & $<.01$ & $46.3 \pm 12.1$ & $39.2 \pm 9.8$ & .03 \\
\hline LVEF, mm & $20.8 \pm 9.5$ & $20.9 \pm 9.2$ & .98 & $21.0 \pm 9.9$ & $19.3 \pm 9.9$ & .53 \\
\hline $\mathrm{AI} \geq \bmod , \mathrm{n}(\%)$ & $31(52.5)$ & $6(12.5)$ & $<.01$ & $21(53.8)$ & $4(20.0)$ & .02 \\
\hline $\mathrm{MR} \geq \bmod , \mathrm{n}(\%)$ & $30(50.8)$ & $9(18.8)$ & $<.01$ & $21(53.8)$ & $6(30.0)$ & .08 \\
\hline $\mathrm{TR} \geq \bmod , \mathrm{n}(\%)$ & $24(40.7)$ & $8(16.7)$ & .02 & $15(38.5)$ & $2(10.0)$ & .02 \\
\hline TAPSE, $\mathrm{mm}$ & $12.0 \pm 5.4$ & $15.4 \pm 5.5$ & $<.01$ & $11.8 \pm 5.2$ & $16.1 \pm 5.3$ & $<.01$ \\
\hline Systolic PA pressure, $\mathrm{mm} \mathrm{Hg}$ & $31.4 \pm 9.3$ & $28.5 \pm 7.9$ & .02 & $30.1 \pm 8.1$ & $25.4 \pm 7.3$ & .02 \\
\hline
\end{tabular}


TABLE E3. Univariate and multivariable analyses for risk factors for developing moderate or greater aortic insufficiency in patients with pre-left ventricular assist device mild aortic insufficiency $(\mathbf{n}=\mathbf{1 1 1})$

\begin{tabular}{|c|c|c|c|c|c|c|}
\hline & \multicolumn{3}{|c|}{ Univariate analysis } & \multicolumn{3}{|c|}{ Multivariable analysis } \\
\hline & $\begin{array}{c}\text { Post-LVAD } \geq \\
\operatorname{Mod} A I n=48\end{array}$ & $\begin{array}{c}\text { Post-LVAD } \leq \\
\text { Mild AI } n=63\end{array}$ & $P$ value & Odds ratio & $95 \%$ CI & $P$ value \\
\hline Age, $y$ & $60.5 \pm 10.6$ & $58.8 \pm 12.0$ & .44 & 1.02 & $0.97-1.06$ & .48 \\
\hline Male, n (\%) & $33(68.8)$ & $45(71.4)$ & .76 & & & \\
\hline BMI, $\mathrm{kg} / \mathrm{m}^{2}$ & $28.9 \pm 5.5$ & $28.4 \pm 5.8$ & .62 & & & \\
\hline $\begin{array}{l}\text { INTERMACS, n (\%) } \\
\quad 1 \\
2 \\
\geq 3\end{array}$ & $\begin{array}{c}18(37.5) \\
26(54.2) \\
4(8.3)\end{array}$ & $\begin{array}{c}22(34.9) \\
36(57.1) \\
5(8.0)\end{array}$ & .68 & & & \\
\hline Ischemic disease, $\mathrm{n}(\%)$ & $22(45.8)$ & $27(42.9)$ & .75 & & & \\
\hline $\begin{array}{l}\text { Indication, n (\%) } \\
\text { BTT } \\
\text { DT }\end{array}$ & $\begin{array}{l}17(35.4) \\
31(64.6)\end{array}$ & $\begin{array}{l}42(66.7) \\
21(33.3)\end{array}$ & $<.01$ & 3.54 & $1.46-8.58$ & $<.01$ \\
\hline $\begin{array}{c}\text { Device, n }(\%) \\
\text { HeartMate } 2 \\
\text { HeartWare }\end{array}$ & $\begin{array}{c}41(85.4) \\
7(14.6)\end{array}$ & $\begin{array}{l}42(66.7) \\
21(33.3)\end{array}$ & .02 & 0.70 & $0.28-2.14$ & .53 \\
\hline Systolic arterial pressure, $\mathrm{mm} \mathrm{Hg}$ & $101.0 \pm 14.1$ & $101.6 \pm 11.2$ & .79 & & & \\
\hline Diastolic arterial pressure, $\mathrm{mm} \mathrm{Hg}$ & $63.9 \pm 8.6$ & $65.1 \pm 10.1$ & .50 & & & \\
\hline Heart rate, beats/min & $87.3 \pm 16.4$ & $91.6 \pm 16.7$ & .18 & & & \\
\hline $\begin{array}{l}\text { NYHA, n (\%) } \\
\text { I } \\
\text { II } \\
\text { III } \\
\text { IV }\end{array}$ & $\begin{array}{c}0 \\
1(2.2) \\
4(8.7) \\
43(89.1)\end{array}$ & $\begin{array}{c}0 \\
0 \\
12(20.0) \\
51(80.0)\end{array}$ & .21 & & & \\
\hline Cardiogenic shock, $\mathrm{n}(\%)$ & $22(45.8)$ & $26(41.3)$ & .63 & & & \\
\hline Resuscitation, $\mathrm{n}(\%)$ & $3(6.3)$ & $1(1.6)$ & .19 & & & \\
\hline Preoperative IABP, n (\%) & $15(31.3)$ & $14(22.2)$ & .28 & & & \\
\hline Preoperative Impella, n (\%) & $4(8.3)$ & $9(14.3)$ & .33 & & & \\
\hline Preoperative ECMO, n (\%) & $4(8.3)$ & $8(12.7)$ & .46 & & & \\
\hline Arrhythmia, n (\%) & $23(47.9)$ & $34(54.0)$ & .53 & & & \\
\hline Diabetes, $\mathrm{n}(\%)$ & $19(39.6)$ & $29(46.0)$ & .50 & & & \\
\hline Dyslipidemia, n (\%) & $33(68.8)$ & 45 (71.4) & .76 & & & \\
\hline Dialysis, n (\%) & 0 & $3(4.8)$ & .13 & & & \\
\hline Hypertension, $\mathrm{n}(\%)$ & $33(68.8)$ & $45(71.4)$ & .76 & & & \\
\hline Lung disease, $\mathrm{n}(\%)$ & $21(43.8)$ & $27(42.9)$ & .93 & & & \\
\hline Cerebrovascular disease, $\mathrm{n}(\%)$ & $14(29.3)$ & $9(14.3)$ & .06 & & & \\
\hline BNP, pg/mL & $1192[572.5-1833.8]$ & $1028.0[616.0-1503.0]$ & .91 & & & \\
\hline \multicolumn{7}{|l|}{ Preoperative echocardiography } \\
\hline Aortic root diameter, $\mathrm{mm}$ & $31.5 \pm 3.8$ & $33.2 \pm 3.5$ & .02 & 1.07 & $0.94-1.22$ & .30 \\
\hline Sclerotic aortic valve, $\mathrm{n}(\%)$ & $18(37.5)$ & $30(47.6)$ & .29 & & & \\
\hline $\mathrm{LAD}, \mathrm{mm}$ & $49.5 \pm 8.1$ & $48.4 \pm 7.1$ & .45 & & & \\
\hline LVEDD, mm & $70.2 \pm 8.5$ & $67.6 \pm 9.1$ & .12 & & & \\
\hline LVDs, mm & $63.3 \pm 9.9$ & $60.5 \pm 10.0$ & .14 & & & \\
\hline RVEDD, mm & $43.1 \pm 8.4$ & $42.6 \pm 9.8$ & .79 & & & \\
\hline LVEF, \% & $19.2 \pm 7.1$ & $17.0 \pm 6.9$ & .10 & & & \\
\hline $\mathrm{MR} \geq \bmod , \mathrm{n}(\%)$ & $32(66.7)$ & $35(57.1)$ & .24 & & & \\
\hline
\end{tabular}


TABLE E3. Continued

\begin{tabular}{|c|c|c|c|c|c|c|}
\hline & \multicolumn{3}{|c|}{ Univariate analysis } & \multicolumn{3}{|c|}{ Multivariable analysis } \\
\hline & $\begin{array}{c}\text { Post-LVAD } \geq \\
\operatorname{Mod} \text { AI } n=\mathbf{4 8}\end{array}$ & $\begin{array}{c}\text { Post-LVAD } \leq \\
\text { Mild AI } n=63\end{array}$ & $P$ value & Odds ratio & $95 \% \mathrm{CI}$ & $P$ value \\
\hline TR $\geq \bmod , \mathrm{n}(\%)$ & $13(27.1)$ & $19(30.2)$ & .72 & & & \\
\hline TAPSE, $\mathrm{mm}$ & $14.7 \pm 4.9$ & $13.6 \pm 5.5$ & .29 & & & \\
\hline Systolic PA pressure, $\mathrm{mm} \mathrm{Hg}$ & $52.2 \pm 15.4$ & $52.1 \pm 14.7$ & .97 & & & \\
\hline \multicolumn{7}{|l|}{ Cardiac catheterization } \\
\hline RA pressure, $\mathrm{mm} \mathrm{Hg}$ & $13.1 \pm 7.2$ & $14.7 \pm 6.4$ & .29 & & & \\
\hline Mean PA pressure, $\mathrm{mm} \mathrm{Hg}$ & $38.7 \pm 11.3$ & $40.5 \pm 8.9$ & .39 & & & \\
\hline Wedge pressure, $\mathrm{mm} \mathrm{Hg}$ & $26.0 \pm 8.4$ & $27.0 \pm 7.8$ & .54 & & & \\
\hline PVR, Wood units & $4.2 \pm 2.3$ & $4.3 \pm 2.1$ & .90 & & & \\
\hline Cardiac index, $\mathrm{L} / \mathrm{min} / \mathrm{m}^{2}$ & $1.7 \pm 0.4$ & $1.8 \pm 0.5$ & .24 & & & \\
\hline \multicolumn{7}{|l|}{ Operative data } \\
\hline Surgical approach, $\mathrm{n}(\%)$ & & & .29 & & & \\
\hline Full sternotomy & $43(89.6)$ & $57(90.5)$ & & & & \\
\hline Partial sternotomy & $4(8.3)$ & $2(3.2)$ & & & & \\
\hline Left thoracotomy & $1(2.1)$ & $4(6.3)$ & & & & \\
\hline \multicolumn{7}{|l|}{ LVAD pump speed, rpm } \\
\hline HeartMate 2 & $9228.2 \pm 395.5$ & $9185.7 \pm 736.7$ & .75 & & & \\
\hline HeartWare & $2795.6 \pm 138.1$ & $2662.1 \pm 200.9$ & .09 & & & \\
\hline LVAD duration, y & $3.6 \pm 2.1$ & $1.7 \pm 1.8$ & $<.01$ & 1.51 & $1.21-1.88$ & $<.01$ \\
\hline Aortic valve nonopening, $\mathrm{n}(\%)$ & $25(52.1)$ & $30(47.6)$ & .64 & 1.25 & $0.75-1.84$ & .55 \\
\hline
\end{tabular}

Continuous variables are presented as mean \pm standard deviation, and categorical variables as number (\%). BNP is presented as median and 25 th-75th quantile. $L V A D$, Left ventricular assist device; $\geq$ mod, moderate or greater; $\leq$ mild, mild or less; AI, aortic insufficiency; $C I$, confidence interval; BMI, body mass index; INTERMACS, Interagency Registry for Mechanically Assisted Circulatory Support; $B T T$, bridge to transplantation; $D T$, destination therapy; $N Y H A$, New York Heart Association; $I A B P$, intra-aortic balloon pump; $E C M O$, extracorporeal membrane oxygenation; $B N P$, brain natriuretic peptide; $L A D$, left atrial dimension; $L V E D D$, left ventricular end-diastolic dimension; $L V D s$, left ventricular end-systolic dimension; $R V E D D$, right ventricular end-diastolic dimension; $L V E F$, left ventricular ejection fraction; $M R$, mitral regurgitation; TR, tricuspid regurgitation; TAPSE, tricuspid annular plane systolic excursion; $P A$, pulmonary artery; $R A$, right atrium; $P V R$, pulmonary vascular resistance. 